\title{
Sarau Virtual: Conceitos Spinozianos e Deleuzeanos no Ciberespaço como Potência Criativa e Afetiva na Pandemia de Covid-19
}

Uillian Trindade Oliveira ${ }^{1}$

\section{Introdução}

EM RAZÃo dA PANDEMIA DE COVID-19, o CIBERESPAÇO E OS PROCESSOS DIGITAIS EMERGIRAM COMO UMA POSSIBILIDADE eficaz para a promoção e manutenção de relacionamentos, lazer, trabalho ou convívio familiar. Para a área artística, não foi diferente: os processos digitais apresentaram-se em possibilidades de experimentação, criação e exposição, de modo que as tecnologias da informação e comunicação (TIC’s) têm se tornado fundamental para estabelecer mediações entre a matéria, o átomo, o digital e o virtual. As relações da criação artística, como o uso de computadores, câmeras digitais, scaners, aplicativos de manipulação de imagens e a transposição para espaço expositivo virtual que se caracteriza como uma prática cultural, serão analisadas neste texto a partir do "Sarau Virtual Mande Notícias", projeto de extensão promovido pela Universidade Federal do Oeste da Bahia (Ufob).

Conforme Oliveira ${ }^{2}$, o "Sarau Virtual Mande Notícias" surgiu como um projeto de extensão para, com poesias e trabalhos visuais, estreitar os laços afetivos entre os membros da comunidade acadêmica da Ufob. Essa ação se deu pela necessidade de reinvenção diante do isolamento social. Entendíamos que, se o vírus e a pandemia extrapolaram fronteiras e, de algum modo, faziamna desaparecer, a arte e a poesia também poderiam embarcar nesse movimento.

O projeto alcançou lugares para além dos muros da Ufob, atingindo outras cidades, outros estados e até outros países. Recebemos "notícias" do interior da Bahia e de estados como Espírito Santo, Minas Gerais, Rio de janeiro, São Paulo, Paraná, Mato Grosso, Goiás, Alagoas. Os limites geográficos do Brasil foram ultrapassados, com "notícias” chegando até nós a partir do Paraguai, Portugal e Estados Unidos. Assim, o convite produziu um evento de contornos multiculturais.

Nesse contexto, remontamo-nos a Deleuze e Guattari ${ }^{3}$, para quem os sentidos de participação podem ser entendidos como estruturas de rizomas ligadas por conexões associativas, sem um eixo central, hierarquia ou linearidade, multiplicando as ramificações e ampliando a interação, a ubiquidade, a percepção, novas conexões e o fluxo de sentidos. Em um rizoma, qualquer ponto se liga a outro, abre-se à recombinação dos signos, em uma relação dialógica.

A exposição virtual ocorreu na noite do dia 5 de junho de 2020, às 19h, na plataforma virtual Google Meet. Ali, encontraram-se pessoas que há muito tempo não se viam bem como aquelas que nunca haviam se visto e estavam se conhecendo naquele momento. No ambiente virtual, por meio de poemas e trabalhos visuais digitalizados, todos compartilharam seus modos de vida, suas formas de reinvenção, angústias e preocupações sobre o momento pandêmico. Mas, acima de tudo, estava a esperança de que um dia a pandemia iria acabar.

Assim, emoções e pensamentos foram expressos em palavras, mas associadas com ilustrações produzidas pelos próprios autores. As palavras ganharam forma em pinturas, fotografias, desenhos, crochês, mosaicos e esculturas de papel machê. Os

\footnotetext{
${ }^{1}$ Professor da Universidade Federal do Oeste da Bahia; artista visual

${ }^{2}$ Oliveira, Uillian Trindade. Catálogo Sarau Virtual Mande Notícias. Santa Maria da Vitória: Ufob, 2020. Disponível em: <https://issuu.com/uilliantrindade/docs/catlogo_sarau_virtual_mande_notcias>. Acesso em: 6 mar. 2021.

${ }^{3}$ DeleuZe, Gilles.; GuATtARI, FÉlIX. Mil platôs: capitalismo e esquizofrenia. v. 1. Rio de Janeiro: Editora 34, 1995.
} 
artistas-poetas hibridizaram os gestos, deslocando seus corpos e trabalhos artísticos orgânico-concretos para um ambiente inorgânico, o ciberespaço.

\section{Os Bons Encontros: Conatus, Afetos, Rizomas e Territórios}

O projeto de extensão "Sarau Virtual Mande Notícias” foi significativo para seus participantes, familiares e amigos, configurando-se como um momento em que todos agiram para ressignificar suas existências em meio à pandemia, experimentando bons encontros por meio do virtual, potencializando-se uns aos outros. A chegada da pandemia diminuiu o conatus, trouxe a tristeza e o padecimento. Aos milhares, pôs-nos em servidão diante do vírus; afastamo-nos, escondemo-nos, cobrimos nossas bocas e narizes, sufocamo-nos; muitos paramos de trabalhar ou deslocamos nosso ambiente laboral para o ambiente íntimo, paramos de ir à rua.

Todavia, o encontro das pessoas pelo meio virtual na exposição vai ao encontro do pensamento do filósofo holandês Baruch de Spinoza (1632-1677), que aborda sobre os bons encontros em sua teoria dos afetos. Na definição III, em seu livro "Ética III", Spinoza ${ }^{4}$ explica que, "Por afeto, compreendo as afecções do corpo, pelas quais sua potência de agir é aumentada ou diminuída, estimulada ou refreada, e, ao mesmo tempo, as ideias dessas afecções”.

Temos, primeiro, a potência de existência, que se abre em potência para produzir; "[...] potência absoluta de pensar, portanto, de compreender, que se prolonga, e potência de compreender tudo o que é produzido”, como postula Deleuze ${ }^{5}$. Com inspiração nesse pensador, reconhecemos, pois, que as pessoas afetam e são afetadas, pois toda potência é ativa e inseparável de um poder de também ser afetado. Essa capacidade de ser afetado encontra-se constantemente permeada por afecções, que são o encontro de um corpo com o outro ou com o mundo que as produz.

Cada pessoa possui um modo de vida, uma fala existencial, interagindo no e com o mundo, que é "[...] substância ou essência do ser, aquilo que é, mas que se concebe em outro por meio de afecções” ${ }^{\text {. }}$. Em meio a essas relações, ocorrem movimentos de potências produtivas na existência. Ou seja, uma infinitude de forças extensivas é determinada do exterior, do meio, a entrar na relação que corresponde à sua essência ou ao seu grau de potência. Essa essência foi denominada por Spinoza ${ }^{7}$ como conatus.

Porém, Deleuze ${ }^{8}$ alerta para o fato de que o conatus não se configura como uma simples tendência ao processo de existir, mas diz respeito a como fazer essa existência potente, criativa para estar se apto a afetar e ser afetado para perseverar na existência. Essa aptidão, conforme o pensador, é o próprio conatus, algo que se mantém aberto a ser afetado, a produzir linhas de fuga, desterritorializações, reterritorializações e territorializações, tal como ocorreu aos participantes do projeto "Sarau Virtual Mande Notícias”, que migraram do mundo real, concreto, para o mundo virtual, com produções que ressignificaram a existência em um momento em que ter incertezas era a única certeza que se tinha.

Todo o processo criativo das pessoas envolvidas no projeto vai ao encontro do conceito de conatus, configurando-se como esforço para vivenciar a alegria, aumentando a potência de agir, imaginar, criar e encontrar o que é causa de alegria, mas

\footnotetext{
${ }^{4}$ SpinOzA, BARUCH. Ética. Tradução de Thomaz Tadeu. Belo Horizonte: Autêntica, 2009, p. 163.

${ }^{5}$ DeleuZe, GiLles. Espinosa: filosofia prática. São Paulo: Escuta, 2002, p. 103.

${ }^{6}$ Ibidem, p. 104.

${ }^{7}$ SPINOZA, BARUCH, op. cit.

${ }^{8}$ DeleuZe, Gilles, op. cit.
} 
também um esforço para afugentar a causa da tristeza vivenciada durante a pandemia. Portanto, "O conatus é esforço para aumentar a potência de agir ou experimentar paixões alegres" ${ }^{\prime \prime}$.

Como esforço bem-sucedido, no caso da participação, criação, exposição e compartilhamento virtual das poesias e trabalhos artísticos, o conatus se chama Virtude, ou seja, o próprio conatus como potência de causa eficiente. Assim, podemos concluir que o conatus, naquela exposição, emerge como o esforço, por meio de linhas de fuga, para usar a expressão de Deleuze $^{10}$, para fazer perseverar a existência e agir racionalmente com responsabilidade, em busca das paixões alegres, conduzindo ao conhecimento com o objetivo de manutenção da vida, às ideias adequadas e à potência dos sentimentos ativos.

Abordada no projeto sob a luz deleuziana, a arte foi entendida como a linguagem das sensações que não possui opinião, mas se faz infiltrar nas coisas ${ }^{11}$. Desse modo, “[...] desfaz a tríplice organização das percepções, afecções e opiniões e a substitui por um monumento composto de perceptos, de afectos, e de blocos de sensações”, conforme postulam Deleuze e Guattari ${ }^{12}$. Esses filósofos são enfáticos ao determinar a tarefa da arte, a saber, "Transmitir para o futuro as sensações persistentes que encarnam o acontecimento: o sofrimento sempre renovado dos homens, seu protesto recriado, sua luta retomada" ${ }^{13}$.

A partir da ética de Spinoza, Deleuze ${ }^{14}$ discorre sobre o que pode um corpo, argumentando que, “[...] quando um corpo encontra outro corpo, uma ideia ou outra ideia, tanto acontece que as duas relações se compõem para formar um todo mais potente, e, ao contrário, quando um decompõe o outro, destrói a coesão das suas partes”.

Com relação às desterritorializações no ciberespaço por meio da arte e poesia, Guattari e Rolnik ${ }^{15}$ explicam que a noção de território pode ser entendida como algo que vai além do seu uso feito pela etologia (ramo da Zoologia que estuda o comportamento animal) e da etnologia (ramo das Ciências Humanas que estuda as características de cada etnia, com a finalidade de estabelecer as linhas gerais da estrutura e da evolução das sociedades). Assim, "os seres existentes se organizam segundo territórios que os delimitam e os articulam aos outros existentes e aos fluxos cósmicos" ${ }^{16}$.

A exemplo do ciberespaço, o território não é um espaço estático, estanque; pode se referir tanto ao espaço vivido quanto à percepção sobre a relação do sujeito com o ambiente. Assim, "ele é o conjunto das representações, percepções e afetos, que vai denotar comportamentos, de investimento, nos tempos e nos espaços sociais, culturais, estéticos e cognitivos” ${ }^{17}$. O território pode se desterritorializar, abrir-se em linhas de fuga, até mesmo modificar seu percurso. Em consequência, a reterritorialização será uma tentativa de restabelecer um território num processo desterritorializante.

A exemplo das diversas formas de que temos lançado mão para nos reinventarmos na pandemia de Covid-19 e que foram potencializadas pelo "Sarau Virtual Mande Notícias", a desterritorialização está constantemente presente na vida humana, forçando o homem a reinventar continuamente sua relação com o meio. Para Rolnik ${ }^{18}$, esse movimento criador se dá em fluxos, pelo encontro dos corpos, por atração e repulsa, um encontro que pode ser entre humanos como também com a matéria, a máquina, a natureza, a poesia, o ciberespaço, a música, um filme, um cheiro, uma dança, um encontro ou

\footnotetext{
${ }^{9}$ DeleuZe, Gilles, op. cit., p. 107.

${ }^{10}$ Deleuze, Gilles, op. cit.

${ }^{11}$ Oliveira, Uillian TRINDADE. Frans Krajcberg: história de vida e processo de criação. Tese (Doutorado em Educação) Universidade Federal do Espírito Santo, Vitória, 2015.

${ }^{12}$ Deleuze, Gilles.; Guattari, FÉlix. O que é a filosofia? Rio de Janeiro: Editora 34, 2010, p. 208.

${ }^{13}$ Deleuze, Gilles.; Guattari, FÉlix, op. cit., p. 209.

${ }^{14}$ DELEUZE, GILles op. cit., p. 25.

${ }^{15}$ Guattari, FÉliX.; ROLNIK, Suely. Micropolítica: cartografias do desejo. Petrópolis: Vozes, 2005.

${ }^{16}$ Ibidem, p. 388.

${ }^{17}$ Ibidem.

${ }^{18}$ ROLNIK, SUELY. Cartografia sentimental. Porto Alegre: Sulina, 2014.
} 
desencontro amoroso. Prosseguindo nessa linha de pensamento, Rolnik ${ }^{19}$ frisa que cada um sabe "o que lhe permite habitar o ilocalizável, aguçando sua sensibilidade à latitude ambiente... É imprescindível que você encontre o seu próprio fator de a(fe)tivação”.

Para compreender esse processo no projeto em análise, seguimos o pensamento de Bruce e Haesbaert ${ }^{20}$, os quais explicam que, em Deleuze e Guattari, a proposta é pensar a territorialização e a desterritorialização como processos paralelos e fundamentais, a fim de compreender as práticas humanas, suas mudanças, as fugas de territórios, seus componentes, suas intensidades e seus agenciamentos nas práticas culturais. Para que não haja uma oposição entre mundo real e mundo virtual neste contexto, os filósofos ainda ratificam que "a desterritorialização de um plano não exclui uma reterritorialização, mas a afirma como criação de uma nova terra por vir" ${ }^{21}$. Podemos considerar a desterritorialização absoluta segundo certas relações, por entender que "as desterritorializações relativas [...] não são cósmicas, mas geográficas, históricas e psicossociais"22.

\section{Processo de Criação dos Participantes: a Criação Material Modificadapelo Digitals Transposto para o Virtual}

Desde a década de 1990, as TIC's têm possibilitado a criação de diversas comunidades virtuais que compartilham gostos comuns, na tentativa de reconstruir suas identidades. Sobre o processo criativo dos participantes do "Sarau Virtual Mande Notícias" na produção de trabalhos artísticos com materiais concretos para transformar suas imagens em digital, expondo-as e compartilhando-as no virtual, lembramos que, para Castells ${ }^{23}$, não há diferença entre real e virtual e a influência de um sobre o outro é um verdadeiro binômio, representado, por exemplo, pela televisão e a nossa realidade.

Os equipamentos para digitalização e compartilhamento de imagens foram integrados ao processo criativo. Contudo, é fundamental compreender que as TIC’s não anulam os objetos materiais, como pincéis, tintas, telas, papel, lápis, cimento, madeira, ferro, ou seja, tudo que ainda se utiliza para produzir um trabalho artístico.

Desta maneira, os processos criativos foram afetados pela iminência da pandemia que se desdobrou na necessidade de adaptação, forçando a criações serem produzidas via processos e equipamentos de digitalização para o ciberespaço.

Neste processo criativo para compor o Sarau, os novos meios de comunicação transformaram radicalmente as maneiras de criação, o tempo e o espaço de interação com as obras de arte, o que caracteriza múltiplos modos de integração na cultura digital/virtual para abarcar as diversas formas de expressão.

[...] Localidades ficam despojadas de seu sentido cultural, histórico e geográfico e reintegram-se em redes funcionais ou em colagens de imagens, ocasionando um espaço de fluxos que substitui o espaço de lugares. O tempo é apagado no novo sistema de comunicação já que, passado, presente e futuro podem ser programados para interagir entre si na mesma mensagem. O espaço de fluxos e o tempo intemporal são as bases principais de uma nova cultura, que transcende e inclui a diversidade dos sistemas de

\footnotetext{
${ }^{19}$ Ibidem, p. 39-40.

${ }^{20}$ Bruce, Glauco.; HAEsBaert, RogéRIO. A desterritorialização na obra de Deleuze e Guattari. Geographia, Rio de Janeiro, v. 4, n. 7, p. 7-22, 2009. Disponível em: <https://periodicos.uff.br/geographia/article/view/>. Acesso em: 3 maio 2021.

${ }^{21}$ Deleuze, Gilles.; Guattari, FÉliX, op. cit., p. 107.

${ }^{22}$ Ibidem.

${ }^{23}$ CASTELlS, MANUEl. A sociedade em rede - a era das informações: economia, sociedade cultura. São Paulo: Paz e Terra, 2007.
} 
representação historicamente transmitidos: a cultura da virtualidade real, onde o faz-de-conta vai se tornando realidade. ${ }^{24}$

Movimento nesse sentido pode ser notado no trabalho da participante Glécia Almeida (Figura 1), em que, a arte manual do crochê, tão presente em Santa Maria da Vitória, interior do estado da Bahia, e outras cidades do interior do Brasil, desloca-se para o virtual.
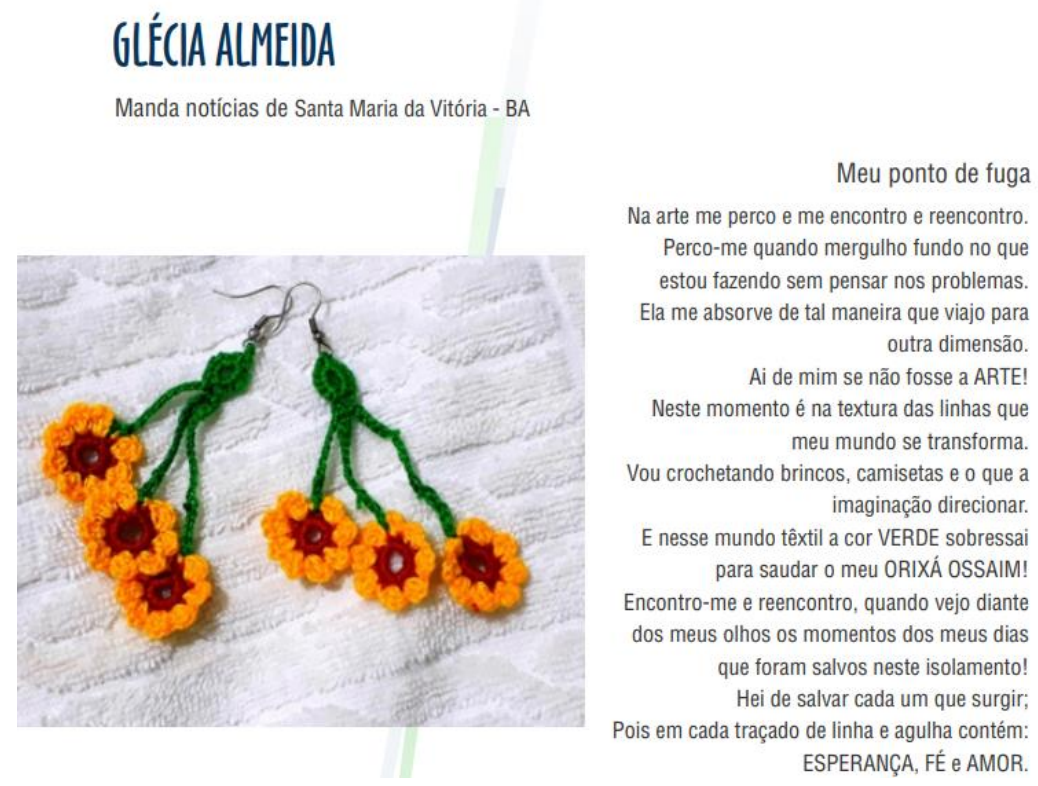

Figura 1 - "Brinco de crochê"

Fonte: OLIVEIRA 25 .

No ciberespaço, o corpo interfaceado é convidado a enfrentar os limites na transição entre o mundo real, com suas criações concretas, sua transformação para o digital, para finalmente, serem expostas e compartilhadas no virtual. Daí em diante, diferentes tipos e níveis de interatividade acontecem, em função do "princípio da mutabilidade, do efêmero, do vir a ser, em processos que demandam reciprocidade, implicação, colaboração, partilhando informações no ciberespaço” ${ }^{26}$. Nessa concepção, a conexão por TIC’s produz em nosso corpo “mutações, imprevisibilidades, dissipações [...] amplia[ndo] a capacidade de sentir [...]"27.

\footnotetext{
${ }^{24}$ Ibidem, p. 462.

${ }^{25}$ Op. cit. Oliveira, Uillian TRINDADE, 2020, p. 26.

${ }^{26}$ Domingues, Diana Maria Gallicchio. Ciberespaço e rituais: tecnologia, antropologia e criatividade. Horizontes Antropológicos, a. 10, n. 21, p. 181-198, jan./jun. 2004. Disponível em: <https://www.scielo.br/scielo.php?script=sci_arttext\&pid=S0104-71832004000100008>. Acesso em: 28 abr. 2021.

${ }^{27}$ Ibidem, p. 182.
} 
O desejo de transpor o físico para o virtual é mais antigo que o ciberespaço. Silva ${ }^{28}$-explica sobre a dualidade espaço físico e virtual que perdurava até a década de 1990. O físico e o concreto eram vistos como opostos, não coincidentes. Com o tempo, essa dualidade transformou-se em uma arte híbrida. No entendimento de Lévy ${ }^{29}$, o ciberespaço não diz apenas sobre a infraestrutura material da comunicação digital, relacionando-se, ainda, às infinitas possibilidades de informações que abriga.

Os suportes de inteligência coletiva do ciberespaço multiplicam e colocam em sinergia as competências. Do design à estratégia, os cenários são alimentados pelas simulações e pelos dados colocados à disposição pelo universo digital. Ubiquidade da informação, documentos interativos interconectados, telecomunicação recíproca e assíncrona em grupo e entre grupos: o ciberespaço faz dele o vetor de um universo aberto. Simetricamente, a extensão de um novo espaço universal dilata o campo de ação dos processos de virtualização ${ }^{30}$.

A Figura 2 mostra mais um trabalho entre os expostos no "Sarau Virtual Mande Notícias", produzida em meio digital com uso de manipulação de imagens.

${ }^{28}$ Silva, AdRIANA DE SOUZA E. Arte, interfaces gráficas e espaços virtuais. ARS (São Paulo), v. 2, n. 4, p. 79-97, 2004. Disponível em: <https://www.revistas.usp.br/ars/article/view/2934>. Acesso em: 11 mar. 2021.

${ }^{29}$ LÈvy, PIERRE. Cibercultura. Tradução de Carlos Irineu da Costa. São Paulo: Editora 34, 2009.

${ }^{30}$ LÈVY. PIERRE op. cit., p. 49-50. 


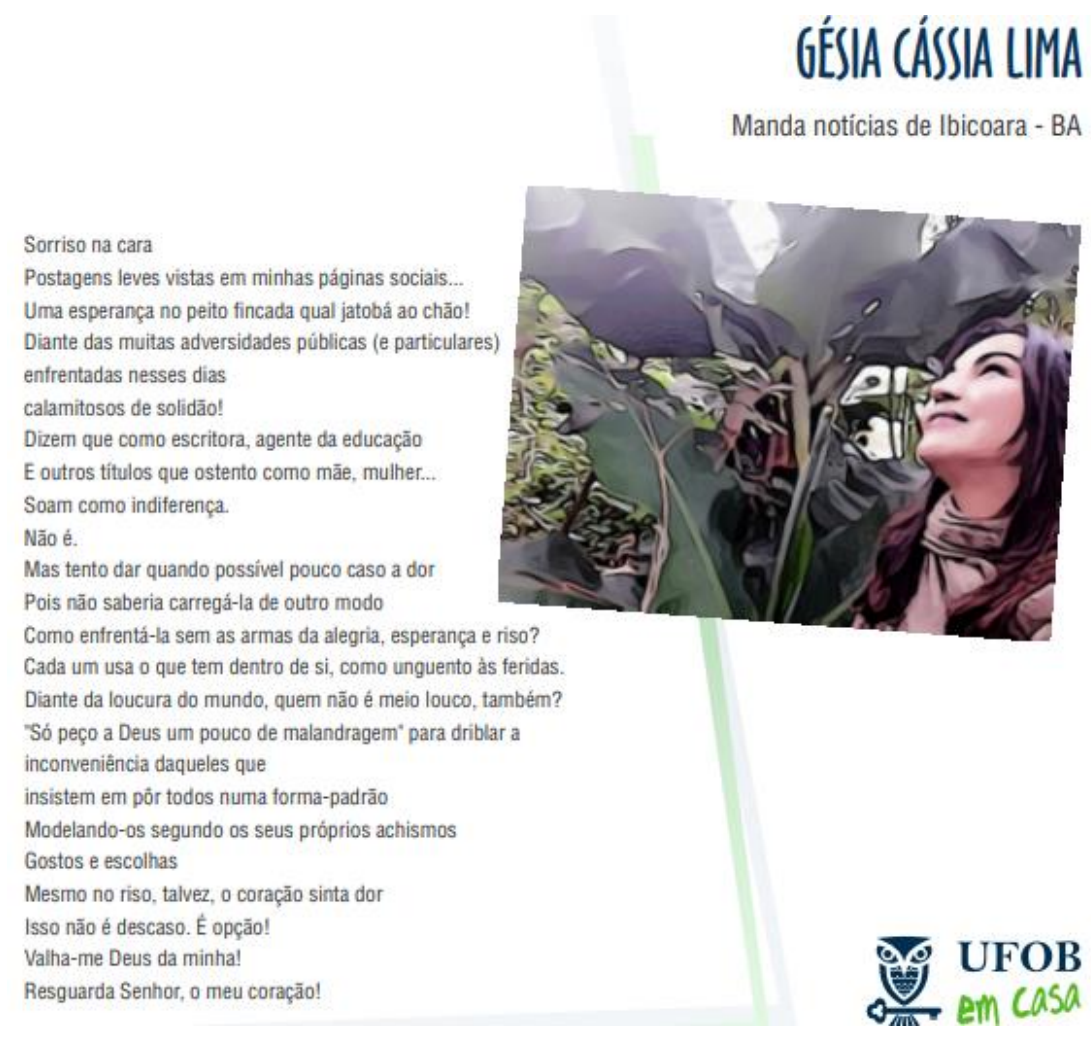

Figura 2 - "Sorriso na cara"

Fonte: OLIVEIRA ${ }^{31}$.

Com a ampliação do acesso às TIC's, as possibilidades de experimentações artísticas com os recursos computacionais expandiram-se $\mathrm{e}^{32}$. O espaço e o tempo de outrora são, hoje, insuficientes, pela própria imposição vivenciada frente à necessidade de distanciamento para conter o avanço do contágio do novo coronavírus. Por isso, foi necessário criar ambientes que dessem conta desse novo espaço perceptivo de cooperação em que artistas e público experimentam, transformam, criam e compartilham novos caminhos de sentir e ver o mundo.

Nesse contexto, lembramos que, frente às mudanças promovidas pelas novas tecnologias em seu próprio tempo, na década de 1960, McLuhan ${ }^{33}$ observou que esse desenvolvimento tecnológico desencadearia transformações profundas na nossa visão e percepção do mundo:

O mundo todo, passado e presente, agora se desvenda aos nossos olhos como uma planta a crescer num filme extraordinariamente acelerado. A velocidade elétrica é sinônimo de luz e do entendimento das causas. Assim, o emprego da eletricidade em situações anteriormente mecanizadas faz com que os homens facilmente descubram padrões e

\footnotetext{
${ }^{31}$ Op. cit. Oliveira, Uillian Trindade, 2020, p. 25.

${ }^{32}$ Arantes, Priscila Almeida Cunha. Percepção do espaço-tempo em ambientes midiáticos. In: FÁtimA, A.; CosTA, Luís Edegar.; Monteiro, Rosana Horio. (Orgs.). Cultura visual e desafios da pesquisa em artes. Goiânia: Anpap, 2005. p. 373-370.

${ }^{33}$ MCLUHAN, MARSHALl. Os meios de comunicação como extensões do homem. São Paulo: Cultrix, 1964, p. 395.
} 
relações casuais, antes impossíveis de serem observadas, devido aos lentos índices de mudanças mecânicas.

Assistimos, nas duas primeiras décadas deste século, um crescente interesse por criações artísticas e exposições por meios de processos digitais em rede. Com o acontecimento da pandemia de Covid-19, expandiram-se as reuniões e exposições por telepresença, criando, assim, um novo território de divulgação artística e cultural. $\mathrm{O}$ artista tende a escapar às adversidades quando sente que seu processo criativo está ameaçado. Assim foi com o advento da tinta a óleo, com a fotografia, com o vídeo e, agora, com o computador e o ciberespaço. São possibilidades que surgem e, em meio a experimentações, acabam sendo convencionalmente incorporadas. No contexto contemporâneo, essa realidade abriu perspectivas para ausência das visitas presenciais, deslocando os sentidos da percepção, do objeto artístico, da curadoria e do público para o campo ampliado do ciberespaço.

Entre o material e o virtual, existe uma hibridização, causada pelo deslocamento do digital, "um momento, uma condição, uma propriedade e uma qualidade que abrange e transcende os novos media ${ }^{34}$. A reprodução da realidade material está marcada pela dispersão, pelos desvios e pela partilha, mediante a digitalização de obras artísticas e espaços que são criados e existem no mundo físico.

Corroborando Rancière ${ }^{35}$, as criações artísticas se tornam perceptíveis por serem determinadas pelo tempo e espaço, que são lugares políticos na medida em que a maneira como aparecem define as configurações de subjetividade e participação política. Seu postulado defende o vínculo entre estética e política a partir do recorte sensível do indivíduo para sua comunidade e o que determina o que pode ser apresentado, compartilhado e fruído. Essas atividades operam para afetar a redistribuição do sensível, dirimir o discurso, para introduzir novas criações e objetos no campo da percepção.

\section{Considerações Finais}

No contexto atual, é fundamental a tomada de consciência de que a forma como nos relacionamos com a arte e seus espaços expositivos está em transição, o que se observa principalmente a partir do início da pandemia de Covid-19. Para reinventar nossos processos criativos e promovermos a exposição das produções artísticas ao mesmo tempo que fazemos o isolamento social para evitarmos a contaminação, estamos nos interfaceando, digitalizando-nos, conectando-nos no ciberespaço.

Nesse movimento, o conatus vivenciado pelos participantes do “Sarau Virtual Mande Notícias” mostrou-se um processo dinâmico da afetividade que aumenta a potência de existir, que se inclina entre o agir e o padecer, escolhendo, porém, afetos ativos: criação, exposição e compartilhamento de obras e poesias que elevam as esperanças em momento de tamanha incerteza. Os participantes escolheram não padecer diante das paixões, desterritorializaram-se para criar e ressignificar seus modos de vida, opondo-se a elas, impondo sua potência de agir, resistindo e persistindo na existência. Reforçam o conatus como o esforço vital por suprimir os obstáculos externos a tudo aquilo que possa impedir a potência de agir.

Neste encontro dos corpos, de potências do existir e das paixões tristes, os artistas expositores do "Sarau Virtual Mande Notícias", pessoas comuns de distintos lugares, conectadas pelo estado incerto que perpassava sua condição naquele momento,

\footnotetext{
${ }^{34}$ Olson, Marisa. Pós-internet: a arte depois da internet. In: BARRAnHa, H.; MARTins, S. S.; Ribeiro, A. P. (Eds.). Museus sem lugar: ensaios, manifestos e diálogos em rede. Lisboa: Instituto de História da Arte - FCSH Universidade Nova de Lisboa, 2015, p. 133.

${ }^{35}$ Rancière, JaCQues. A partilha do sensível: estética e política. Tradução de Mônica Costa Netto. 2. ed. São Paulo: Editora 34, 2009.
} 
escolheram migrar voluntariamente para o ciberespaço e participar de um grupo, em uma relação dialógica entre seus corpos e as TIC’s, com o objetivo de afetar e serem afetadas numa ética de potencialização dos afetos alegres, compondo a exposição.

Essa experiência nos convida a refletir sobre como as TIC's têm proporcionado novas maneiras de nos relacionarmos com esse ambiente expandido pela interatividade virtual, o qual afeta nossa percepção. O “Sarau Virtual Mande Notícias”, por meio da telepresença, mostra que a nova maneira de interação possibilitada pelo ciberespaço e suas interfaces modifica o contexto social de produção e fruição da arte. É uma interatividade que convida o homem a interagir com a máquina e seus artifícios em ambientes tecnologizados, que expandem o fruir arte por meio das tecnologias digitais.

Levando-se em consideração todo o exposto, em eventos como o que foi alvo da análise neste texto, o corpo é convidado a atuar a distância, expandindo-se para o virtual. Este se configura como uma nova maneira de afetar e ser afetado em espaços criativos e expositivos, que nos leva a uma percepção diferente da que tínhamos antes. Agora habitamos o mesmo espaço, paradoxalmente de diferentes lugares; o distante tornou-se próximo. Somos nômades, somos um, somos muitos, com lugar, sem lugar, afetando e sendo afetados em fluxos constantes, persistindo no ato de existir e resistir.

\section{Referências bibliográficas}

Arantes, Priscila Almeida Cunha. Percepção do espaço-tempo em ambientes midiáticos. In: FÁtima, A.; Costa, Luís Edegar.; Monteiro, Rosana Horio. (Orgs.). Cultura visual e desafios da pesquisa em artes. Goiânia: Anpap, 2005. p. 373-370.

Bruce, Glauco.; Haesbaert, RogÉRIo. A desterritorialização na obra de Deleuze e Guattari. Geographia, Rio de Janeiro, v. 4, n. 7, p. 7-22, 2009. Disponível em: <https://periodicos.uff.br/geographia/article/view/>. Acesso em: 3 maio 2021.

Castells, Manuel. A sociedade em rede - a era das informações: economia, sociedade cultura. São Paulo: Paz e Terra, 2007.

DELEUZE, GILlES. Espinosa: filosofia prática. São Paulo: Escuta, 2002.

DeleuZe, Gilles.; GUATTARI, FÉLIX. O que é a filosofia? Rio de Janeiro: Editora 34, 2010.

DeleuZe, Gilles.; GUATTARI, FÉLIX. Mil platôs: capitalismo e esquizofrenia. v. 1. Rio de Janeiro: Editora 34, 1995.

Domingues, Diana Maria Gallicchio. Ciberespaço e rituais: tecnologia, antropologia e criatividade. Horizontes Antropológicos, a. 10, n. 21, p. 181-198, jan./jun. 2004. Disponível em: <https://www.scielo.br/scielo.php?script=sci_arttext\&pid=S0104-71832004000100008>. Acesso em: 28 abr. 2021.

GuatarRi, FÉliX.; RolniK, Suely. Micropolítica: cartografias do desejo. Petrópolis: Vozes, 2005.

LÉVY, PIERRE. Cibercultura. Tradução de Carlos Irineu da Costa. São Paulo: Editora 34, 2009.

MCLUHAN, MARSHALl. Os meios de comunicação como extensões do homem. São Paulo: Cultrix, 1964.

OliVEIRA, UILLIAN. TRINDADE. Frans Krajcberg: história de vida e processo de criação. Tese (Doutorado em Educação) Universidade Federal do Espírito Santo, Vitória, 2015.

Oliveira, Uillian. Trindade. Catálogo Sarau Virtual Mande Notícias. Santa Maria da Vitória: Ufob, 2020. Disponível em: <https://issuu.com/uilliantrindade/docs/catlogo_sarau_virtual_mande_notcias>. Acesso em: 6 mar. 2021. 
Olson, MARISA. Pós-internet: a arte depois da internet. In: BARRANHA, H.; MARTINS, S. S.; RIBEIRO, A. P. (Eds.). Museus sem lugar: ensaios, manifestos e diálogos em rede. Lisboa: Instituto de História da Arte - FCSH Universidade Nova de Lisboa, 2015. p. 123-136.

RANCIÉRE, JACQUES. A partilha do sensível: estética e política. Tradução de Mônica Costa Netto. 2. ed. São Paulo: Editora 34, 2009.

ROLNIK, SUELY. Cartografia sentimental. Porto Alegre: Sulina, 2014.

Silva, Adriana. De SouZA. e. Arte, interfaces gráficas e espaços virtuais. ARS (São Paulo), v. 2, n. 4, p. 79-97, 2004. Disponível em: <https://www.revistas.usp.br/ars/article/view/2934>. Acesso em: 11 mar. 2021.

SPINOZA, BARUCH. Ética. Tradução de Thomaz Tadeu. Belo Horizonte: Autêntica, 2009. 